\title{
ACUTE TOXICITY DUE TO OCCUPATIONAL EXPOSURE TO THE PLANT GROWTH REGULATOR HYDROGEN CYANAMIDE (CASE REPORT)
}

\author{
By \\ El Mahdy NM and Kharoub HS \\ National Egyptian Center of Environmental and Toxicological Research (NECTR),
}

\section{Cairo University}

Corresponding author : El Mahdy NM: nashwa.elmahdy@kasralainy.

\begin{abstract}
Introduction: Pesticides are widely used throughout the world and around 1-5 million cases of pesticide poisoning are estimated annually among agricultural workers, most of them happens in developing countries. In the latter, the use of pesticides is about $20 \%$ of the total world consumption since 1980 and it has been increasing annually. Dermal exposure is the most relevant route of exposure for pesticide applicators. Dormex is a plant growth regulator with Hydrogen cyanamide $(\mathrm{CH} 2 \mathrm{~N} 2)$ as an active ingredient. Despite its extensive use in agriculture, little is known about the health effects of exposure to hydrogen cyanamide. The U.S. Environmental Protection Agency (EPA) places hydrogen cyanamide, into the highest toxicity category (toxicity category I) because of its corrosive effects on the skin and eyes. In addition, it was experimentally proved that hydrogen cyanamide has systemic toxic effects on the liver, kidney and thyroid in addition to its effect on hemopoeitic system. Aim of work: The aim of this work is to provide awareness about the adverse health effects of hydrogen cyanamide. Case report: At Kasr Al Ainy hospital we reported a case of acute hydrogen cyanamide poisoning causing severe cutaneous reactions in a young male due to occupational exposure. The patient was managed under intensive care with supportive treatment as no specific antidote is available for this type of poisoning, and then the patient was referred to the dermatology department for management of skin injury that necessitated treatment for more than 2 months. Conclusion and recommendations: Rapid and aggressive management is crucial for cases of Dormex toxicity especially that there is no specific antidote for it. Lack of awareness of adverse health effects of hydrogen cyanamide and improper handling pose the risk of toxicity which can be prevented by taking appropriate precautionary measures against the exposure.
\end{abstract}

Key words: Pesticide poisoning, Developing countries, Hydrogen cyanamide, Dormex Occupational exposure and Cutaneous reactions. 


\section{Introduction}

In developing countries, the use of pesticides is about $20 \%$ of the total world consumption since 1980 and it has been increasing annually (WHO, 2014). Around 1-5 million cases of pesticide poisoning are estimated annually among agricultural workers, most of them happened in developing countries (Abdou and Abo El-Atta, 2018).

Dormex is a plant growth regulator with Hydrogen cyanamide (CH2N2) as an active ingredient. It was first registered for use in 1984 (Bradbury, 2007). Despite its extensive use in agriculture, little is known about the health effects of exposure to hydrogen cyanamide. It is commercially sold as a blue liquid, which contains $50 \%$ hydrogen cyanamide. It can be sprayed on dormant grape vines that causes chemical vernalization and uniform bud break. Hydrogen cyanamide shows $100 \%$ oral bioavailability by laboratory animals. The average absorbed dermal doses in 24 hours in humans and rats were $5.5 \%$ and $11.1 \%$, respectively.

Hydrogen cyanamide is highly toxic. The exact mechanism of action of this compound has not been established. Animal studies have indicated that at cellular level, cyanamide is activated by catalase, which in turn causes catalase inhibition an enzyme whose normal function was to remove excess hydrogen peroxides. The inhibition of this process resulted in oxidative damage and uncoupling of oxidation and phosphorylation (De Zwart et al., 1999; Mohy et al., 2000)

The substance also inhibits aldehyde dehydrogenase and can produce Disulfiram-like syndrome (e.g., vomiting, parasympathetic hyperactivity, dyspnea, hypotension, and confusion) when exposure coincides with alcohol use (Lorenzo et al., 2006; de Haro, 2009).

Health effects resulting from Dormex exposure vary according to the type of exposure: via dermal, oral or inhalational routes. However, dermal exposure is the most relevant route of exposure for pesticide applicators (van Hemmen and Brouwer, 1995; Lebailly et al., 2009). Toxic effects from contact include severe irritation and ulceration of skin, eyes, gastrointestinal and respiratory tracts (CDC, 2005). It can cause severe cutaneous reactions such as Erythema Multiforme (EM), Stevens Johnsons Syndrome (SJS) and Toxic Epidermal Necrolysis (TEN). The U.S. Environmental Protection Agency (EPA) places both the active ingredient (hydrogen cyanamide) and the commercial product (Dormex), into the highest toxicity category (toxicity category I) because of its corrosive effects on the skin and eyes (EPA, 2003).

Systemic poisoning by hydrogen cyanamide may cause parasympathetic over-activity. In large doses circulatory depression and coma are possible (MSDS, 2005) 


\section{Aim of work}

The aim of this work is to provide awareness about the adverse health effects of hydrogen cyanamide through presenting a case report, especially that there is no specific antidote for it.

\section{Consent}

A written consent was taken from the patient's relative to document the case with photos for scientific purposes.

\section{Ethical approval}

The case report was approved by the director of NECTR, Kasr Al Ainy Hospital, Faculty of Medicine, Cairo University.

\section{Case report:}

On the same day, on January 2019; three cases of acute occupational exposure to hydrogen cyanamide presented to the Emergency department of the National Egyptian Center of Environmental and Toxicological Research (NECTR) with different degrees of corrosive cutaneous reactions. We presented the most severe case with detailed history and investigations. This was a 28 -yearsold male farmer who presented with history of exposure to the plant growth regulator hydrogen cyanamide. The detailed history of the present illness revealed that the patient used Dormex by spraying in the agricultural field. After use, he didn't change his clothes or took a shower and slept for 2 hours. So prolonged skin contact occurred.

On admission, patient was stuporous only responding to painful stimuli. Initial assessment revealed Glasgow Coma Scale (GCS) score of 10/15, pulse of 97 beats/min, blood pressure of $110 / 70 \mathrm{mmHg}$, respiratory rate of $16 /$ min and oxygen concentration of $98 \%$ in supine position. He had occasional spontaneous jerky movements. Pupils were $5 \mathrm{~mm}$ and bilaterally reactive. The remaining physical examination did not reveal any significant findings. Skin examination showed first and second degree burns on the trunk, upper abdomen and on both arms.

Full laboratory investigations were done. They are represented in Table (1). Blood gas analysis revealed metabolic acidosis. Computerized tomography (CT) brain was done and revealed brain edema. Serum pseudocholinesterase was measured and showed normal level.

Patient was admitted in the intensive care unit, treated with supportive therapy including analgesics, antiemetics, antibiotics and corticosteroids. Patient received mannitol infusion to decrease intracranial pressure, $300 \mathrm{ml}$ mannitol $20 \%$ as loading dose then $150 \mathrm{ml} / 8$ hour for 48 hours with follow up of creatinine level. Specific dermal treatment was given after dermatological consultation for the corrosive effects of Dormex which included antiseptic skin preparations, topical antibiotic and hyaluronic acid skin preparations. Patient stayed for 8 days in NECTR then he was referred to the dermatology department to manage corrosive skin effects that necessitated treatment for more than 2 months till complete resolution occurred. 
Table (1): Results of laboratory investigations performed in the first 6 days after admission.

\begin{tabular}{|c|c|c|c|c|c|c|}
\hline Investigations & Day 1 & Day 2 & Day 3 & Day 4 & Day 5 & Day 6 \\
\hline $\begin{array}{c}\text { Hemoglobin (g / } \\
\text { dl) }\end{array}$ & 19.5 & & 13.7 & 11.4 & 11.1 & 11.2 \\
\hline Hematocrite (\%) & 42.8 & & 40.6 & 28.3 & 27.2 & 27.4 \\
\hline MCV & 71.3 & & 85 & 67.3 & 67.7 & 67.9 \\
\hline $\operatorname{MCHC~(g/dl)~}$ & 43.2 & & 34 & 40.2 & 40.8 & 40.8 \\
\hline WBC $(10 * 3 / u L)$ & 21.6 & & 11.7 & 9.8 & 4.9 & 13.1 \\
\hline Lymphocytes (\%) & 17.6 & & 15 & 31 & 41.1 & 39.9 \\
\hline Monocytes (\%) & 3.9 & & 4 & 12.7 & 11.4 & 10.9 \\
\hline Granulocytes (\%) & 78.5 & & 77 & 56.3 & 47.5 & 49.2 \\
\hline $\begin{array}{c}\text { Platelets }(10 * 3 / \\
\text { uL) }\end{array}$ & 196 & & $48(\mathrm{D})-16(\mathrm{~N})$ & 54 & 57 & 165 \\
\hline ABG & MA & Normal & Normal & Normal & Normal & \\
\hline Sodium & 135 & & 140 & 140 & 137 & \\
\hline Potassium & 4.6 & & 4.1 & 4.1 & 3.8 & \\
\hline RBS & 130 & & 152 & 145 & 181 & 93 \\
\hline ALT & 85 & 189 & 190 & 88 & 45 & 28 \\
\hline AST & 68 & 197 & 202 & 8 & 32 & 24 \\
\hline Urea & 36 & & 29 & 22 & 39 & 32 \\
\hline Creatinine & 0.8 & & 0.7 & 1.8 & 0.8 & 0.7 \\
\hline Pseudo Ch.E. & 3500 & & & & 4000 & \\
\hline PT & & 13.6 & 12.4 & 16.9 & 13.8 & 13.2 \\
\hline PC \% & & 80 & 92.5 & 56 & 77 & 85 \\
\hline INR & & 1.21 & 1.07 & 1.66 & 1.2 & 1.15 \\
\hline
\end{tabular}


MCV: Mean corpuscular volume MCHC: Mean corpuscular hemoglobin concentration WBC:

White blood cells

AST: Aspartate aminotransferase

MA: Metabolic acidosis

PC\%: Prothrombin concentration

ALT: Alanine aminotransferase

ABG : Arterial blood gases

PT: Prothrombin time

$\mathrm{D}=$ day

$\mathrm{N}=$ night

\section{Reference values of laboratory investigations:}

Aspartate aminotransferase $(\mathrm{AST})=$ up to $38 \mathrm{U} / \mathrm{L}$.

Alanine aminotransferase $(\mathrm{ALT})=$ up to $40 \mathrm{U} / \mathrm{L}$.

Urea $=15-50 \mathrm{mg} / \mathrm{dl}$.

Creatinine $=0.5-1.5 \mathrm{mg} / \mathrm{dl}$.

Sodium $=136-145 \mathrm{mM} / \mathrm{L}$.

Potassium $=3.5-5.0 \mathrm{mM} / \mathrm{L}$.

Prothrombin time $(\mathrm{PT})=12.3 \mathrm{~s}$.

Prothrombin concentration $(\mathrm{PC})=$ 80-100\%.

International normalized ratio $(\mathrm{INR})=1.0-1.2$.

Hemoglobin= 11-16 g/dl

Hematocrite $=36-48 \%$

$\mathrm{MCV}=80-96 \mathrm{fl}$

$\mathrm{MCHC}=32-36 \mathrm{~g} / \mathrm{dl}$

$\mathrm{WBC}=4-11(10 * 3 / \mathrm{uL})$

Lymphocytes $=20-40 \%$

Monocytes $=1-15 \%$

Granulocytes $=50-70 \%$ 


\section{Illustrating figures:}

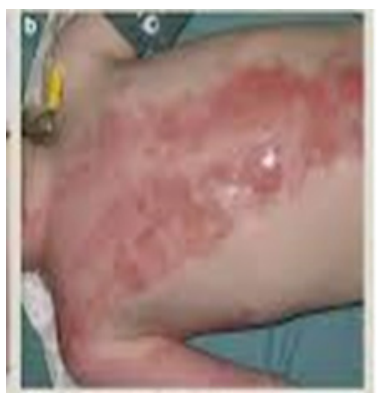

Figure (1): Picture of the patient, 4 hours after exposure to the chemical showing marked erythema and cutaneous burns on the chest and upper abdomen.

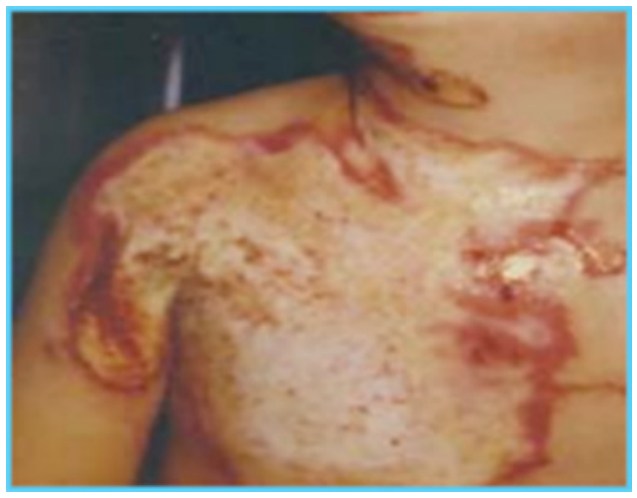

Figure (2): Picture of the patient, 10 hours after exposure showing exfoliation of the skin with septic infection and yellowish pus on the edges of the lesion. 

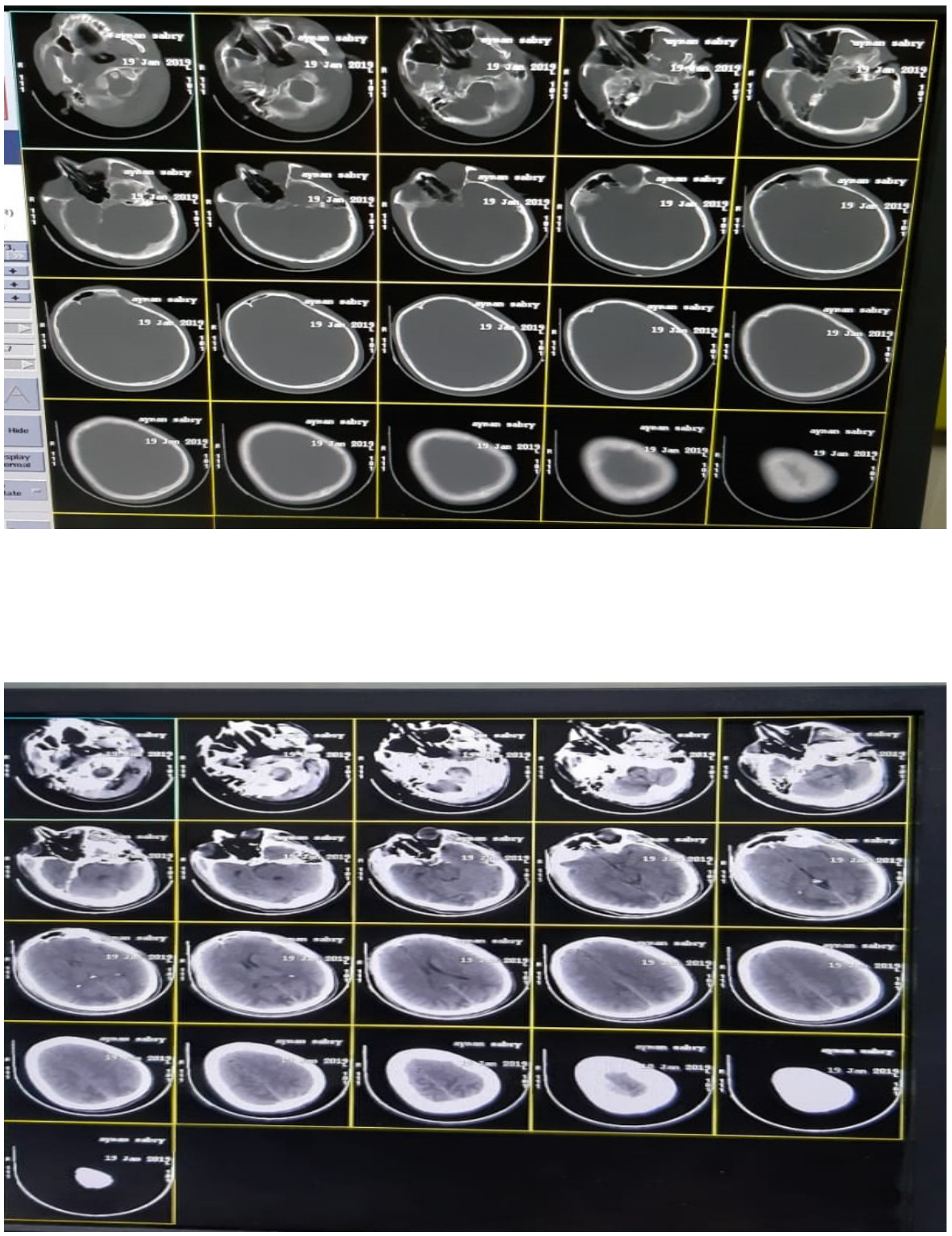

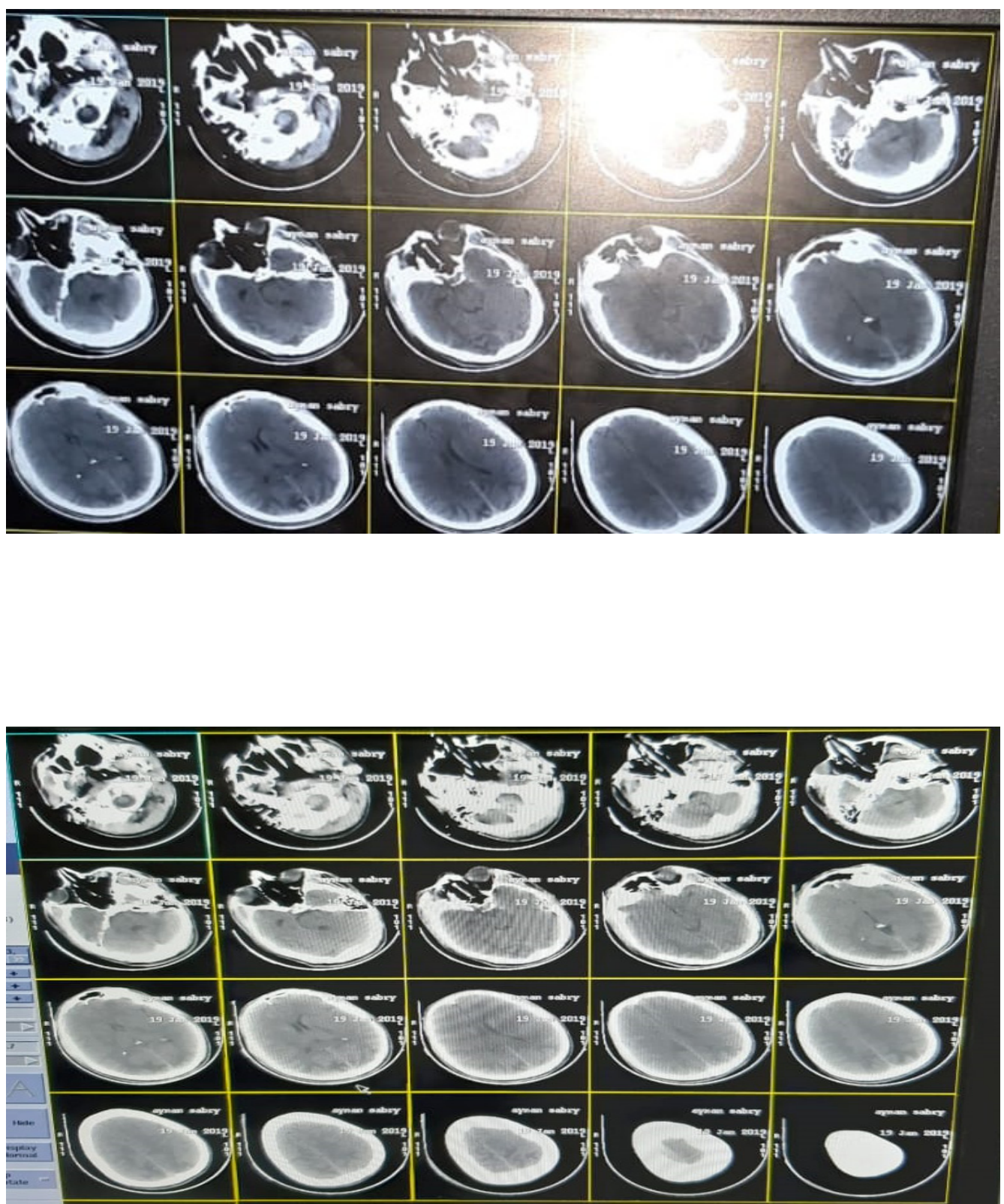

Figure (3): CT scan of the brain showed brain edema. 


\section{Discussion}

Although insecticide poisoning has been reported worldwide, there are limited reports of poisoning with the plant growth regulator-hydrogen cyanamide (CDC, 2001; Inamadar and Patil, 2007).

Several studies proved dermal toxicity in patients receiving cyanamide for treatment of chronic alcoholism. Kawana in 1997 reported seven patients with skin eruptions induced by cyanamide, one of whom showed lichen-planus-like eruption. Aguilar and his colleagues in 1999 reported a case of 52 years old man who presented with a Lichenoid drug eruption that appeared 10 days after he had begun taking cyanamide for treatment of high alcohol intake. Also, Navarro and his colleagues in 2014 reported a case of allergic dermatitis from cyanamide used for chronic alcoholism detoxification. So, dermal toxicity is evident even with oral intake.

In the current case, the patient was involved in mixing and application of Dormex in a grape vine yard. He didn't use any protective devices or precautious measures to protect his exposed body. In addition, he didn't change his clothes or took a shower at the end of his work even he slept for 2 hours. So his body was exposed to dormex for a long period. After awakening, he noticed burning sensation in the chest, abdomen and his back in addition to giddiness. $\mathrm{He}$ was transferred to NECTR, examined and was admitted in ICU ward. On examination, it was found that he had developed severe cutaneous reactions in the form of marked erythema and cutaneous burns as shown in Figure (1). Ten hours after exposure, we noticed exfoliation of the skin with septic infection and pus formation as shown in Figure (2). Similarly Foti and his colleagues in 2008 reported a case of 28-year-old healthy non-atopic man who developed severe skin eruptions following accidental penetration of a small amount of Dormex through the patient's gloves during application in the field. On admission blood pressure was within normal but it showed progressive decrease on the third and fourth day indicating systemic effect of Dormex, the patient was treated with vasopressors and sodium chloride infusion till normalization of the blood pressure.

Regarding investigations done to the patient, there was significant progressive increase in the liver enzymes, AST and ALT from day 1 up to day 5 indicating liver toxicity. Liver 
toxicity was reported by Bruguera et al. in 1987 who found portal and periportal inflammatory changes and fibrosis in biopsy specimens of the hepatocytes of nine asymptomatic alcoholics who were on treatment with cyanamide. Similarly experimental study done by Mohy and co workers in 2000; which proved alteration in liver enzymes in rats acutely intoxicated with hydrogen cyanamide. Also, the study of Gamaluddin and working staffs in 2012 which was done on 12 patients with acute Dormex toxicity admitted to Ain Shams hospital during 4 years period showed highly significant rise of AST and ALT in moderately and severely intoxicated patients. The cause of liver injury was attributed to cytolysis and cell necrosis caused by hydrogen cyanamide exposure and lead to liberation of various hepatic enzymes, [elevated aminotransferases (AST and ALT)] which indicated hepatocellular damage (Krefetz, 2000).

The level of Prothrombin time and International Normalized Ratio increased in the affected patient during the first 3 days then the concentration decreased on the fourth day (Table 1). This could be explained as PT is commonly increased in liver disease because the liver is unable to manufacture adequate amounts of clotting factors or due to disruption of bile flow due to inadequate absorption of vitamin $\mathrm{K}$ from the intestine (Fody, 2000).

In the present study blood picture showed normal hemoglobin level on the first day after admission but it decreased on subsequent days (Table 1). There was significant increase of WBCs count but the platelets were significantly decreased. The high WBCs count could be explained by the inflammatory response of the body which was also noticed by Mitani and his working team in 2005 who reported a case with marked leukocytosis and eosinophilia associated with generalized eruption after cyanamide intake.

Marked decrease in platelets count was observed in our patient (Table 1), this could be due to decreased production of platelets as a result of decreased thrombopoietin due to underlying liver and renal toxicities. Thrombopoietin is a glycoprotein hormone produced mainly by the liver and the kidney that regulates the production of platelets by the bone marrow (Cheung et al., 2005).

Experimental studies done by Cochran and his colleagues in 1993 revealed that hydrogen cyanamide caused toxic effects in the liver, kidney 
and thyroid in addition to hematological effects including decline in red blood cell count and hemoglobin, and toxic effects on granulocytes and platelets. Similar findings were present in the preset case which showed increase in granulocytes level (Table 1).

Pseudocholinesterase level was done to exclude organophosphate toxicity due to similarity in parasympathetic over activity between the two compounds (CDC, 2001) and it was found that Pseudo-cholinesterase level was within normal range indicating parasympathetic over-activity induced by hydrogen cyanamide toxicity.

Conclusion and recommendations:

Based on the current study, it was clear that severe toxicity may develop following occupational exposure to hydrogen cyanamide (Dormex), in the form of severe cutaneous reactions, hepatic dysfunction and hematological toxicity, which may point to the urgent need to enforce occupational health and safety measures among exposed workers.

Also, due to lack of awareness of adverse effects, agricultural workers may not be compliant with protective measures. Efforts are needed to ensure use of personal protective equipment (PPE) in the form of appropriate gloves and clothes to reduce absorption. Accordingly, agricultural workers exposed to hydrogen cyanamide should be provided with adequate information about hydrogen cyanamide related health effects, encourage them to attend training programs, to use appropriate PPE and the importance of preventive measures including change of clothes and skin decontamination after pesticide application and use.

The majority of agricultural pesticide poisoning cases remain unknown due to lack of reporting. Continuous surveillance by health authorities for pesticides' use helps to control, reduce occupational exposure and the occurrence of adverse effects and toxicities among occupationally exposed pesticide end users. Steps should be taken to restrict or ban their usage.

\section{References}

1- Abdou KA and Abo El-Atta HM (2018): Epidemiology of Pesticides in Developing Countries. Adv Clin Toxicol; 3(1): 1-8.

2- Aguilar A, Gallego MA and Piqué E (1999): Lichenoid drug eruption due to cyanamide. Int J Dermatol; 38(12):950-1.

3- Bradbury S (2007): Hydrogen cyanamide summary document registration review initial docket number EPA-HQOPP-20071014. Available at: www. regulations.gov 
4- Bruguera M, Parés A, Heredia D and Rodés J (1987): Cyanamide hepatotoxicity. Incidence and clinico-pathological features. Liver; 7(4):216-22.

5- Centers for Disease Control and Prevention (CDC) (2001): Pesticide-related illnesses associated with the use of a plant growth regulator-Italy MMWR. Morb Mortal Wkly Rep; 50 (39): 845-7.

6- Centers for Disease Control and Prevention (CDC) (2005): CDC Update: Hydrogen cyanamide -related illnesses - Italy, 20022004.MMWR; 54(16):405 -8.

7- Cheung R, Mc Auley R and Pollard J (2005): High mortality rate in patients with advanced liver disease independent of exposure to general anesthesia. J Clinical Anesthesia; 17(3): 172-6.

8- Cochran RC, Leung P, Moore TB, Miller CD, Patterson GT, et al. (1993): Hydrogen Cyanamide: Risk Characterization Document. Medical Toxicology and Worker Health and Safety Branches. Department of Pesticide Regulation California Environmental Protection Agency. Available at:

- https://www.cdpr.ca.gov/docs/whs/active_ ingredient/index.htm

9- de Haro L (2009): Disulfiram-like syndrome after hydrogen cyanamide professional skin exposure: Two case reports in France. J Agromedicine; 14:382-4.
10- De Zwart L, Vermeulen P, Hermanns C, Commandeur JN, Salemink PJ et al. (1999): Urinary excretion of biomarkers for radical induced damage in rats treated with NDMA or diquat and effects of calcium carbimide coadministration. Chem Biol Interact; 117(2):151-72

11- Environmental Protection Agency (EPA) (2003): Information Statistics. Washington; 43: 254-8.

12- Fody EP (2000): Liver function. In: Clinical Chemistry Principles, Procedures, and Correlations. Bishop ML, Engelkirk JD and Fody EP (eds), 4th edition, Lippincott Williams and Wilkins. pp: 354-69.

13- Foti C, Bonamonte D, Conserva A, Pepe ML, Soleo L et al. (2008): Allergic Contact Dermatitis with a Fertilizer Containing Hydrogen Cyanamide (Dormex). Cutaneous and Ocular Toxicology; 27(1):13.

14- Gamaluddin HA, Mahmmoud SM, Mosa ME, Halawa HM and Khalifa EA (2012): A Clinical Study of Acute Hydrogen Cyanamide Toxicity in the Period between 2006-2009 in the Poison Control Center, Ain Shams University. Ain Shams Journal of Forensic Medicine and Clinical Toxicology; 19:97-103

15- Inamadar AC and Patil A(2007): Cutaneous reactions simulating erythema multiforme and Stevens Johnson syndrome due to occupational exposure to a plant growth regulator. Indian J Dermatol Venereol Leprol; 73(5):330-2. 
16- Kawana S (1997): Drug eruption induced by cyanamide (carbamide): a clinical and histopathologic study of 7 patients. Dermatol; 195(1): 30-4.

17- Krefetz RG (2000): Enzymes. In : Clinical Chemistry Principles, Procedures and Correlations. Bishop ML, Engelkirk JD and Fody EP, (eds), 4th edition , Lippincott Willliams and Wilkins. pp:185-214

- Lebailly P, Bouchart V, Baldi I, Lecluse Y, Heutte $\mathrm{N}$ et al.(2009): Exposure to pesticides in open-field farming in France. Ann Occup Hyg; 53: 69-81.

18- Lorenzo de la Peña L, Montero Santos JM, Benito Lozano M and Martín Cabrera F (2006): Acetaldehyde syndrome after laboral exposition to hydrogen Cyanamide. Med Clin (Barc); 127: 717-8.

19- Mitani N, Aihara M, Yamakawa Y, Yamada M, Itoh N et al (2005): DrugInduced Hypersensitivity Syndrome Due to Cyanamide Associated With Multiple Reactivation of Human Herpesviruses. J Med Virology; 75:430-4.
20- Mohy EM, Osman HS and El Hady AM (2000): Cyanamide Toxicity. Role of Alpha Tocopherol Antioxidant. New Egyptian journal of medicine. DOI: 232088361. Available at: https://www.researchgate. net/publication/232088361_Cyanamide_ Toxicity_Role_of_Alpha_Tocopherol_ Antioxidant

21- Material Safety Data Sheet (MSDS) (2005): Cyanamide MSDS available at: http://www.sciencelab.com/msds.

22- Navarro GB, Faraudo EB, Monzón AC and Cisteró-Bahima A (2014): Allergic dermatitis from cyanamide for chronic alcoholism detoxification. Dermatitis; 25(2):100-1.

23- van Hemmen JJ and Brouwer DH (1995):Assessment of dermal exposure to chemicals. Sci Total Environ; 168: 131-41.

24- World Health Organization (WHO) (2014): Chemicals of public health concern in the African Region and their management, Regional Assessment Report. Available at: (https://apps.who.int/ iris/handle/10665/178166). 